\title{
Bipolar DC Power Conversion: State-of-the-Art and Emerging Technologies
}

Rivera, Sebastian; Lizana, Ricardo; Kouro, Samir; Dragicevic, Tomislav; Wu, Bin

Published in:

IEEE Journal of Emerging and Selected Topics in Power Electronics

Link to article, DOI:

10.1109/JESTPE.2020.2980994

Publication date:

2021

Document Version

Peer reviewed version

Link back to DTU Orbit

Citation (APA):

Rivera, S., Lizana, R., Kouro, S., Dragicevic, T., \& Wu, B. (2021). Bipolar DC Power Conversion: State-of-the-Art and Emerging Technologies. IEEE Journal of Emerging and Selected Topics in Power Electronics, 9(2), 1192 1204. https://doi.org/10.1109/JESTPE.2020.2980994

\section{General rights}

Copyright and moral rights for the publications made accessible in the public portal are retained by the authors and/or other copyright owners and it is a condition of accessing publications that users recognise and abide by the legal requirements associated with these rights.

- Users may download and print one copy of any publication from the public portal for the purpose of private study or research.

- You may not further distribute the material or use it for any profit-making activity or commercial gain

- You may freely distribute the URL identifying the publication in the public portal 


\title{
Bipolar DC Power Conversion: State-of-the-Art and Emerging Technologies
}

\author{
Sebastian Rivera, Member, IEEE, Ricardo Lizana, Member, IEEE, Samir Kouro, Senior Member, IEEE, \\ Tomislav Dragicevic, Senior Member, IEEE, and Bin Wu, Fellow, IEEE
}

\begin{abstract}
This paper provides a detailed analysis of the power electronics solutions enabling bipolar dc grids. The bipolar dc grid concept has proven to be more efficient, flexible and higher in quality than the conventional unipolar one. However, despite its many features, these systems still have to overcome their issues with asymmetrical loading to avoid voltage imbalances, besides meeting regulatory and safety requirements that are still under development. Advances in power electronics and the large-scale deployment of de consumer appliances has put this growing architecture in the spotlight, as it has drawn the attention of different research groups recently. The following pages provide an insightful discussion regarding the topologies that enable these architectures, their regulatory requirements besides their features and level of development. Additionally, some future trends and challenges in the further development of this technology are discussed to motivate future contributions that address open problems and explore new possibilities
\end{abstract}

Index Terms-Bipolar DC bus, DC Distribution, DC microgrids, Smart grid, Low voltage DC.

\section{INTRODUCTION}

$\mathbf{T}$ HE SEARCH for sustainable ways of generating electricity while promoting a transversal use of clean technologies is deeply transforming the electric system [1], [2]. The decarbonization of the electric energy market is not only promoting the large-scale deployment of renewable energy sources (RES) in the generation matrix, but also advocating for the modernization at the consumers end . These changes are being enabled by an extensive use of power electronics, providing fast and precise responses to changes in generation, or tightly regulating the power being provided to the loads [3], [4]. This directly translates into a more complex ac power system, posing challenges in terms of reliability, safety and stability [3]. These reasons have motivated the re-evaluation of using low voltage direct-current (LVDC) active grids at distribution level.

Sustainable distributed generation systems such as photovoltaic and wind, as well as energy storage systems can be

S. Rivera is with the Faculty of Engineering and Applied Sciences, Universidad de los Andes, 7620086 Santiago, Chile (e-mail: s.rivera.i@ieee.org).

R. Lizana is with the Department of Electrical Engineering, Universidad Catolica de la Santisima Concepcion, 4090541 Concepcion, Chile, e-mail: ricardolizana@ucsc.cl

S. Kouro is with the Department of Electronic Engineering, Universidad Tecnica Federico Santa Maria, 2390123 Valparaiso, Chile (e-mail: samir.kouro@ieee.org).

T. Dragicevic is with the Department of Electrical Engineering, Denmark Technical University, 2800 Kgs. Lyngby, Denmark (e-mail: tomdr@elektro.dtu.dk).

B. Wu is with the Department of Electrical, Computer and Biomedical Engineering, Ryerson University, Toronto, ON M5B2K3, Canada, e-mail: bwu@ee.ryerson.ca integrated more directly (fewer conversion stages) into dc distribution systems [2] . Furthermore, most of the existing loads both at industrial and residential level are either inherently dc in nature or ac fed through an inverter [5]. In addition, other rising applications such as large-scale data centers [5]-[10], electric vehicle charging infrastructure [11]-[17] or Net Zero Energy Buildings [18]-[21], also have the boosted interest in dc distribution systems [22], [23]. The fact that the integration of the different generators, loads and storage systems into dc networks require fewer conversion stages (in many cases just one), do not require synchronization or reactive power control (just voltage regulation), have lower control complexity, smaller footprint (less transformers and filters), and are more immune to power quality issues, compared to ac systems, have also been factors driving the attention towards de distribution systems [24], [25]. Because all the aforementioned reasons, they could have a significant impact on the performance, efficiency, reliability, power density, and cost of future power systems [5], [7], [8], [26].

Despite the fact that virtually all of the existing consumer appliances or industrial equipment is designed and standardized for ac systems, or the protections and safety-related issues remain a big concern for dc grids, some important signs toward a dc shift have appeared over the last years. Among the pioneers in this regard, the European Union, has defined the voltage limits between $75 \mathrm{~V}$ and $1500 \mathrm{~V}$ for LVDC systems (LVD 2014/35/EU) [27]. Moreover, the Netherlands is the first country that published a national practice guideline for LVDC systems [28], establishing voltage levels for distribution dc grids: $350 \mathrm{~V}$ to $1400 \mathrm{~V}$ with respect to earth for monopolar and bipolar grids, defining zones within the grid to set the ground for protections and safety, imposing the requirement of galvanic isolation between ac and dc parts, and is currently preparing guidelines for safe working and inspection of $\mathrm{dc}$ installations. Other organization making significant efforts in the same direction is the International Electrotechnical Commission, which through several committees are working to standardize common practices for dc installations [29]. Finally, the Institute of Electrical and Electronics Engineers and EMerge Alliance, are also among other important stakeholders committed to advance towards a more de distribution based power system [2].

Currently there are two mainstream dc distribution architectures or configurations, namely the unipolar (also known as monopolar) and the bipolar [30]. The first is characterized by providing a single de voltage level between two conductors, while the second generates two dc voltages across a three-wire 


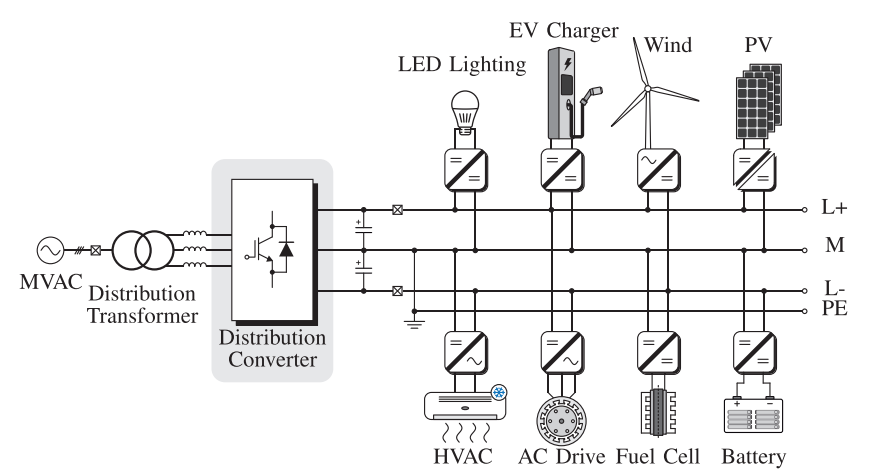

Figure 1. General structure of a low-voltage bipolar dc grid

configuration [31], [32]. Unipolar dc networks are inherently less complex in structure and easier to control, but lack the flexibility and resilience given by the three wire approach, which enables operation under a line fault, and provide a more options for loads and distributed generation, due to the two different voltage levels [31]. Furthermore the bipolar configuration enables both the implementation of a lower dc bus voltage or a higher dc bus voltage, depending which set of two wires are used for connection [31], reducing the voltage conversion range requirements of the connected loads and generators making the operation of power converters more efficient [26]. This also allows a broader range of applications to be interfaced with existing of-the-shelf power converter technology.

One of the major challenges for dc systems is related to protections against short circuit faults and grounding [30]. Again, the bipolar dc configuration provides an advantage over unipolar, due to the existing neutral conductor [22], enabling an easier and faster clearance against faults [22], [32], [33]. On the other hand, the three-wire two-voltage configuration of bipolar grids can lead to voltage unbalances between both voltage levels, given that both loads and generators connected to each pole can draw or inject different power levels causing the imbalance if not addressed properly [15], [32], [34]. Imbalances are usually solved by controlling properly the current circulating through the neutral or middle conductor, which affects the efficiency [35]. The voltage imbalance and its control remains as one of the main challenges facing this technology [25], and will be further elaborated in this paper in the following sections.

Considering the tremendous potential that bipolar LVDC grids hold for the development of dc distribution systems, this paper focuses on providing a state-of-the-art overview of the latest developments, by addressing their main features and drawbacks, while addressing open problems and opportunities that can provide a reference for researchers and practicing engineers on where this technology is heading.

The remainder of this paper has the following structure: Section II presents a discussion of bipolar LVDC systems, including a brief description of the requirements imposed by developing regulation. Section III covers topological aspects of the different converters involved in such grids. Then, future trends and upcoming works are presented in section
IV. Finally, section V presents the summary of the study, and highlights the main contributions of this paper.

\section{BIPOLAR TYPE DC DISTRIBUTION SYSTEMS}

The bipolar architecture for dc distribution networks offers interesting features over the conventional unipolar counterpart. This structure is exhibited in Fig. 1, and it is seen that the utility ac voltage is converted to dc with the use of a distribution transformer and an active rectifier, also called distribution converter. Then, at dc level the system adopts a threewire structure composed by the positive conductor $(\mathrm{L}+)$, the negative conductor (L-) and the neutral conductor (M). Please note that despite the higher complexity of the bipolar grid, this configuration presents clear advantages in terms of efficiency, reliability, safety and transmission capacity when compared to conventional two-wire systems, as it will be demonstrated through the paper. Advances in power electronics and their decreasing costs have allowed an increased penetration of power converters in different applications, thus enabling the consequent expansion of dc systems at distribution level [22].

Among the benefits offered by the system displayed in Figure 1, the main feature is its the three-wire configuration. This resembles the traditional ac system in the sense that it provides the connection to two different regulated voltages. The voltage between the positive and negative poles is analogous to the line-to-line voltage, while the voltage of a pole with respect to the neutral connector is analogous to the phase-to-neutral one [32]. This allows to accommodate a wide set of DGs and loads with different voltage and power ratings combinations in a single dc network [36]-[38].

From an economical point of view, bipolar systems secure the cost competitiveness of the converters interfacing the different stages of the network. This is related with the reduction of the voltage ratings of the power electronic components, the efficiency improvement due the reduction of the rated current, besides the elimination of unnecessary dc-ac stages [26]. The latter is because most of the stages involved in DGs are either dc-based, e.g., photovoltaic (PV) panels, fuel cells (FC) and batteries or generate outputs with variable voltage/frequency, e.g., wind, small hydro, wave/tidal energy conversion systems, hence require power electronics devices to accommodate their output to network conditions [26]. In addition, the presence of batteries and storage stages further enhances the benefits of dc distribution, as it yields to greater efficiency improvements [39], [40] and enhanced stability [30]. The result is a substantial enhancement in the quality of the electric system and at the same time, reduction of the costs when compared to conventional ac solutions [31].

The aforementioned resemblance with three-phase ac systems is also beneficial for the migration process to bipolar dc networks. Considering a conventional TN-S grounded threephase system, which requires five conductors for its realization (three phase conductors, one neutral and the protective earth or grounding conductor). These available cables can serve in a retrofitted dc system that will be superior in terms of power ratings capability and efficiency than the original one [26]. For example, a typical multi-wire $230 \mathrm{~V}$ ac installation 


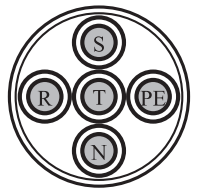

(a)

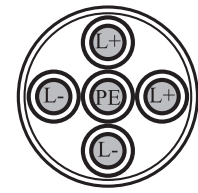

(b)

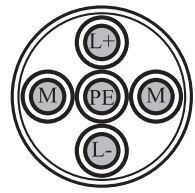

(c)
Figure 2. Cable disposition in retrofitted or new dc systems (a) LVAC cable. (b) Unipolar LVDC cable. (c) Bipolar LVDC cable.

uses $300 \mathrm{~V} / 500 \mathrm{~V} 10 \mathrm{~A}$ cables, following the disposition in Fig. 2(a). The system is then rated for $6.21 \mathrm{~kW}$ (assuming a power factor of 0.9). If such system would be replaced by (a) a $350 \mathrm{~V}$ dc network or (b) a $\pm 350 \mathrm{~V}$ dc network, using the configurations shown in Figures $2(b)$ and 2(c), the power transfer capability will be enhanced to $7 \mathrm{~kW}$ in both cases, with no considerations for reactive power and using the same cables. However, bipolar dc system cables only have to withstand $10 \mathrm{~A}$ while the unipolar one should handle $20 \mathrm{~A}$, hence a different wire gauge or additional conductors will be required. This illustrates one the benefits of bipolar structures over the unipolar ones. Another example is provided in Table I, where different low-voltage ac and dc configurations are compared in terms of voltage and power ratings considering the same cable gauge.

Besides the operational requirements of these grids, the availability of guidelines imposes certain regulatory requirements which can positively impact the conception of new ideas. According to [28], the selection of the dc voltages to be used in LVDC grids is $350 \mathrm{~V}, 700 \mathrm{~V}$ and ultimately $1400 \mathrm{~V}$, to keep these networks within existing LV directives [27], [29] while still allowing room for the presence potentially larger loads. Moreover, these voltages levels are not employed in ac systems, hence recognizing each system is unambiguous and indirectly improves safety measures. The selection of $350 \mathrm{~V}$ also ensures compatibility with existing appliances, because an important part of $230 \mathrm{~V}$-ac-designed equipment can safely work
Table I

COMPARISON OF Low-Voltage AC AND DC CONFigurations [28]

\begin{tabular}{ccc}
\hline LVDC & LVAC & Power capacity $^{1}$ \\
\hline \hline Unipolar 350 V & $230 \mathrm{~V}, 1 \mathrm{ph}$ & $5.6 \mathrm{~kW} \mathrm{dc} / 3.7 \mathrm{~kW} \mathrm{ac}$ \\
Unipolar 700 V & $400 \mathrm{~V}, 3 \mathrm{ph}$ & $11.2 \mathrm{~kW} \mathrm{dc} / 11.1 \mathrm{~kW} \mathrm{ac}$ \\
Bipolar $\pm 350 \mathrm{~V}$ & & \\
Bipolar $\pm 700 \mathrm{~V}$ & $690 \mathrm{~V}, 3 \mathrm{ph}$ & $22.4 \mathrm{~kW} \mathrm{dc} / 19.1 \mathrm{~kW} \mathrm{ac}$ \\
\hline 1. The power rating is calculated assuming 16 A RMS cables.
\end{tabular}

at $350 \mathrm{~V} \mathrm{dc}$ without further modifications besides eliminating the front ends.

Important advances have also been made toward protection of active grids, which still remains as an important barrier for the LVDC shift. In this direction, the aforementioned standard defines safety zones or risk classes within the system, as exhibited in Fig. 3 in order to quantify and classify the different hazards at dc level. Consequently, it can be seen that depending on the zone different protection mechanisms or disconnection times are required, which are properly identified with labels. This division allows to train installers properly and also take the corresponding measures for protection in each case. Moreover, two voltage ranges are clearly defined for LVDC systems: Extra-Low Voltage (ELV), covering from 0 to $120 \mathrm{~V}$ dc: and Low Voltage (LV) which considers sources from 120 up to $1500 \mathrm{~V}$ dc. Depending on this criteria, each zone will allow the presence of sources in these two voltage classes. Additionally, [28] imposes the presence of a galvanic barrier between the ac and dc parts to further ensure security.

On the other hand, the remarkable increase and flexibility provided by USB-C protocol, which is able to power up to $100 \mathrm{~W}$ devices and has bidirectional power flow capabilities, allows to feed an important amount of devices and appliances. The widespread of this protocol also relieves the need for additional protection, given its galvanic isolation and output voltage up to $20 \mathrm{~V}$.

Another requirement that applies to LVDC systems is

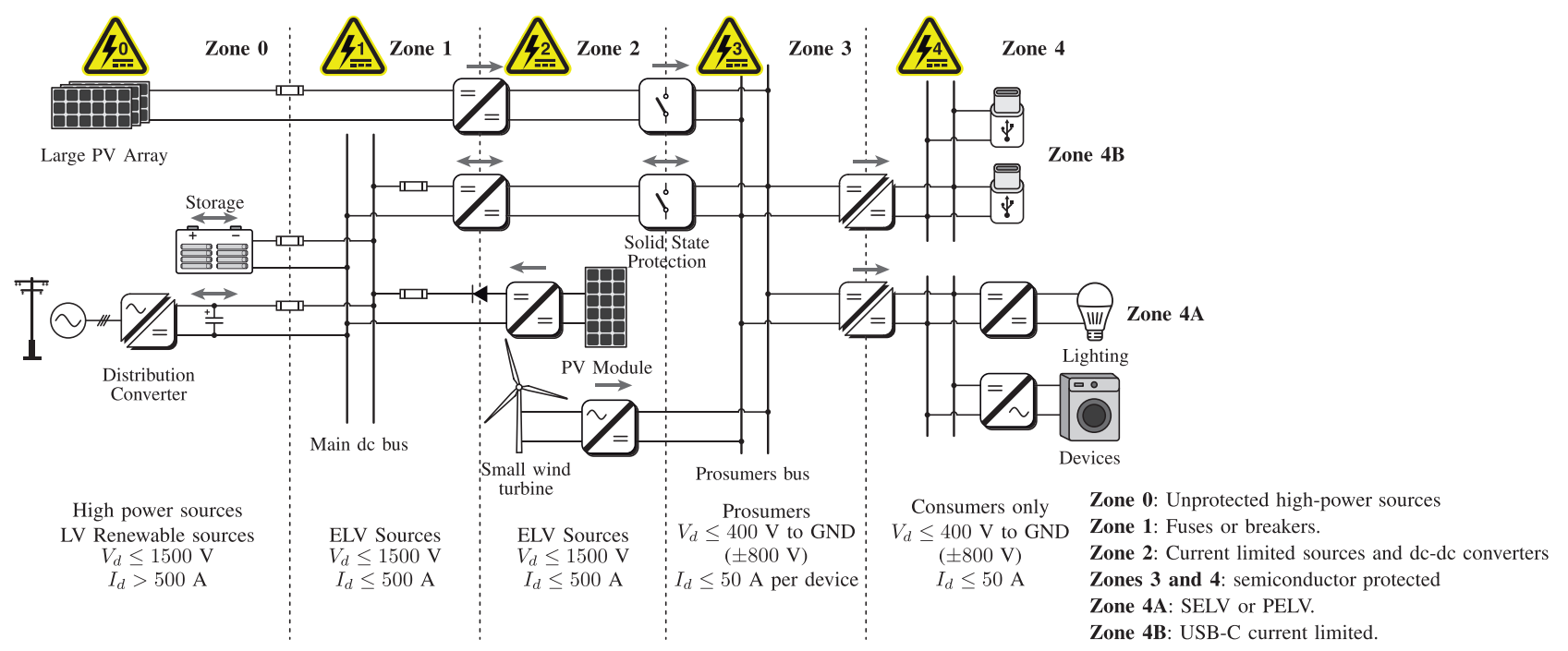

Figure 3. Safety zones or risks classification example according to NEN NPR 9090 [28] 


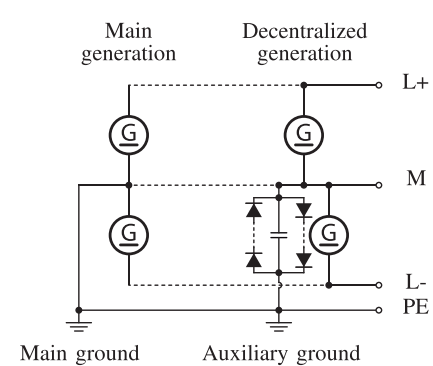

(a)

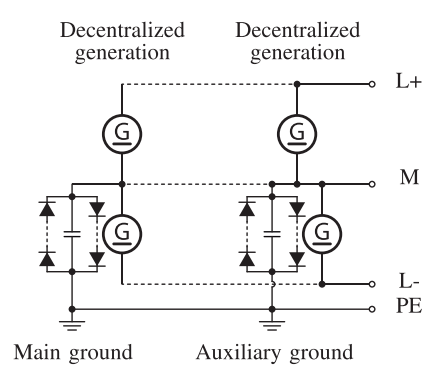

(b)
Figure 4. Grounding schemes for LVDC systems with several sources: (a) TN-SCD for systems with a main generation unit. (b)TN-SCDD for systems with several equivalent decentralized generation units.

related with their grounding mechanism. Grounding LVDC systems is a complex issue, and it is mostly used for the detection of ground faults and for personnel and equipment safety [41], [42]. Similar to ac grids, a TN-S system is preferred for dc given the relatively easy detection of ground faults. Based on the previous risk classification and the associated DC zone classification, TN-S is preferred in DC zones 1 to 3 and 4A. Systems in DC zone 4B are usually implemented as an IT system in practice, because of the USB-C connection. In addition, depending on the case, multiple connections should be made whenever multiple sources are interacting [28]. However, this is not straightforward in dc, given that it opens the possibility of ground leakage currents, caused by a voltage drop in the neutral connector and leads to corrosion and poor efficiency. In such cases, the grounding should be made using anti-parallel diode arrays. As shown in Fig. 4, there are two multiple-grounding schemes: TN-SCD and TN-SCDD. In the first structure, the main source is grounded directly, while the decentralized ones are done through a capacitordiode array. In the later where there is no main source, all of them are grounded using this method. Please note that the diodes should withstand the system's short circuit current, hence these schemes are possible for zones 2 and 3, given that separate decentralized sources are not allowed in zones with higher risks without extensive safety and protection measures.

Overall, the existence of regulatory requirements further improves the development of new solutions, given that besides the typical operational aspects, it allows designers and developers to consider also the safety measures the system should provide, hence facilitating the generation of new bipolar concepts or converters.

\section{TOPOLOGIES AND OPERATIONAL ASPECTS OF BIPOLAR LVDC GRIDS}

Power electronics are essential for achieving the modernization of the electrical system. The power converters allow the presence of dc-based equipment, along with variable voltage/frequency distributed generators connected to the electrical grid. For these reasons, it is important to provide a topological analysis of the different stages involved in a dc network architecture. In this section, the distribution converters that enable the split-dc bus networks and balancing converters, which perform the power consumption relocation to keep the system balanced will be covered and briefly discussed.

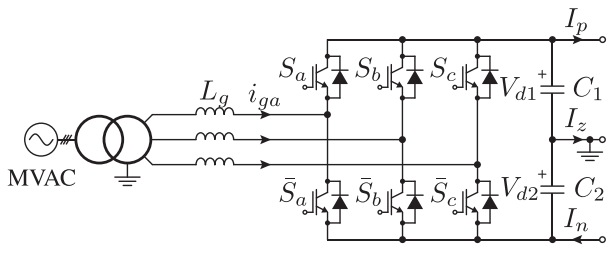

Figure 5. 2L-VSC with neutral line connected to dc midpoint

\section{A. Distribution converter topologies}

Modern active rectifiers offer the advantages of unity power factor, high compactness, high efficiency, and sinusoidal input currents. In this sense, the role of the distribution converter is essential in the dc network of Fig. 1, as it controls and manages the power on the LVDC grid [32], [43], [44]. Therefore, a typical distribution converter does more than simply the grid integration and dc voltage regulation. Given the increased requirements imposed in distributed generation systems, these stages should also provide an adjustable power factor, bidirectional power handling, high-quality input currents and dc voltage, reduced filtering requirements while simultaneously providing high reliability and a reduced device count [12], [13]. Additionally, LVDC applications are interfacing loads typically rated at tens of kilowatts, and supplied from buses in the $400 \mathrm{~V}$ range, hence are subject to stringent harmonic content levels, besides operation at unity power factor becomes mandatory [10].

Despite several topologies are able to act as the rectifier stage of the system, only two alternatives will be analyzed in detail: the two-level voltage source converter (2L-VSC) and the three-level neutral point clamped (3L-NPC) converter. This lies in their proven cost-effectiveness, efficiency and reliability, besides being the two most widespread three-phase converters employed in the industry [43].

\section{B. Two-level voltage source converter}

The converter displayed in Fig. 5 can be found in numerous industry applications as an active front end. As displayed, the circuit consists of six switching devices, typically IGBTs, and a dc-link capacitor. The presence of these active switches, together with a proper control scheme and line filters, generates sinusoidal currents at the input side, along with adjustable power factor and bidirectional power flow [45]. This converter also steps up the dc-voltage to higher values than the input grid voltages, so it is also referred to as a boost type rectifier. Despite its versatility, the reduced quality of the voltage generated impacts the THD of the input current, as larger active/passive filters or higher switching frequencies are needed in order to meet the requirements imposed by the grid code. However, this may reduce the cost-effectiveness and efficiency of the system.

Several 2L-VSC based implementations of dc bipolar grids can be found [32], [34], [35], [43], [46]-[48]. Among the options explored, the simplest approach for implementing a bipolar system is through the use of two cascaded 2L-VSC and a multi-winding transformer, as exhibited in Fig. 6 [49][51]. In this configuration, each $2 \mathrm{~L}-\mathrm{VSC}$ is employed to 


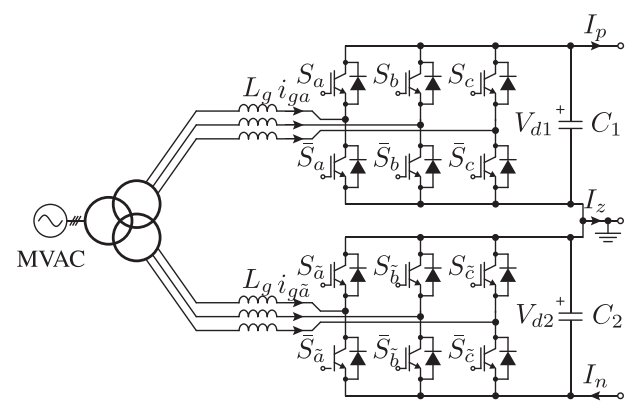

Figure 6. Cascaded 2L-VSC with bipolar dc output

enable independent dc voltage sources. Consequently, this leads to independent operation of the positive and negative poles, hence there are no issues during asymmetrical operation. However, this alternative is not the preferred method for operating as the distribution converter. Despite the simplicity of the operation offered by the cascaded connection, this implementation requires additional hardware, as two separate converters along with the distribution transformer based in two isolated windings. This additional hardware produces an increase in the cost, size and volume of the total system. Additionally, the topology in Fig. 6 requires its secondary windings to be designed to withstand the dc offset caused by the series connection of the converters and the asymmetries that could arise in loads being fed [48].

A single 2L-VSC can also generate a bipolar dc output, but requires additional circuitry. These circuits are all based in the generation of alternative paths for the returning currents, which otherwise flow through the dc bus midpoint during asymmetrical operation and cause dc voltage imbalances. The system exhibited in Fig. 5 does it by connecting to the neutral point of the transformer with the dc bus midpoint. This additional current path allows the regulation of the midpoint current, in order to prevent dc bus voltages from drifting and maintain their proper regulation. However, the generation of non-zero dc currents at the ac side can lead to transformer saturation and thereby it should be strictly limited. To avoid this issue, different approaches have been proposed in the literature [32], [34], [35], [43], [47], [48], both based in passive or active methods, the latter ones enabled by power electronics. The main solutions will be covered in the upcoming sections.

\section{Three-level neutral point clamped converter}

The 3L-NPC converter is another power topology with a widespread application in industry. Originally, the 3L-NPC was proposed for MV drives, but in the last years, this converter found his way to lower voltage and power ranges, mainly in PV applications. Its versatility and functionality in a wide voltage-power combination make it a natural candidate to act as the distribution converter with high-power handling capabilities [52].

From the power circuit displayed in Fig. 7, each phase of the 3L-NPC converter is composed by four switching devices, which can either be IGBTs or MOSFETs, and two diodes connected to the neutral point. This allows to obtain three

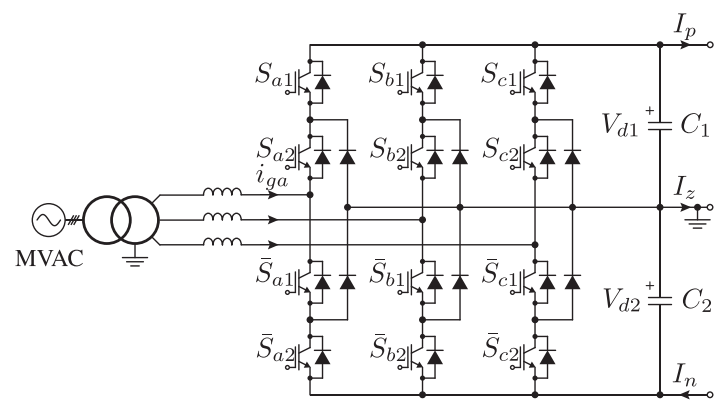

Figure 7. Grid-connected three-level neutral point clamped converter.

voltage levels in the synthesized voltage, hence increasing the voltage quality and fulfill the grid connection quality requirements. However, the proper regulation of this floating neutral voltage represents a critical aspect for the 3L-NPC. Otherwise, the generated voltage becomes distorted, worsening the power quality and also potentially damaging the switching devices. These reasons have motivated important efforts in the literature to solve this matter [53]-[55].

The selection of this topology as the distribution converter of the dc network in Fig. 1, besides its well-known features is the possibility of providing certain room for unbalanced bipolar dc bus operation [15], [16], [43], [53]. When feeding a bipolar de network, this topology is able to absorb current through its neutral point. This is done by injecting a de bias in the phase-to-neutral voltage, hence extending the operation of the active distribution network to a certain range of asymmetries. However, this midpoint current capability is limited to a fraction of the dc current being fed, i.e., the asymmetrical scenarios that the system can handle while keeping the midpoint voltage controlled are limited and dependent of the amplitude modulation index [15], [43].

The unbalanced operation limitation is well defined for this converter, and it can be used as a foundation for the balancing scheme [15]. Unlike the previous converter, this topology can contribute to the balancing of the buses, leading to two different kinds of balancing strategies that extend the operation of the network. Despite both approaches require additional circuitry they differ in the balancing efforts made by the stages. Following the balancing schemes for the $2 \mathrm{~L}-\mathrm{VSC}$, one possibility is to make all the balancing efforts with the added circuits, through a virtual disconnection of the neutral point from the unbalanced loads. In this way, the 3L-NPC focuses on regulating the input currents and power quality while the dc voltages remain unaltered. This leads to higher current stresses on the balancing stages, so interleaving channels can be promoted in order to reduce their ratings [16], [17], [56].

A different concept is to implement a coordinated balancing scheme, where both the central converter and the balancing stages share the current redistribution efforts [15], [38]. The balancing principle is the same as with the $2 \mathrm{~L}-\mathrm{VSC}$, and the exceeding current should be redistributed by the means of a power converter stage. The dc-link structure opens the possibility to three-level dc-dc stages as it will be covered in the upcoming section. 


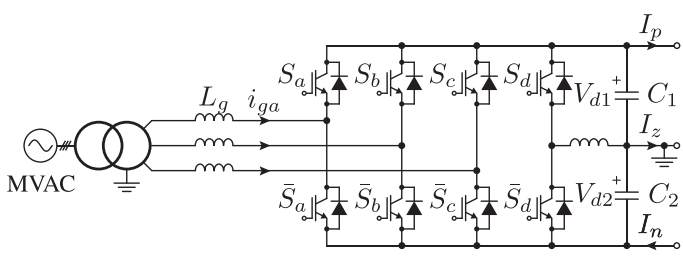

(a)

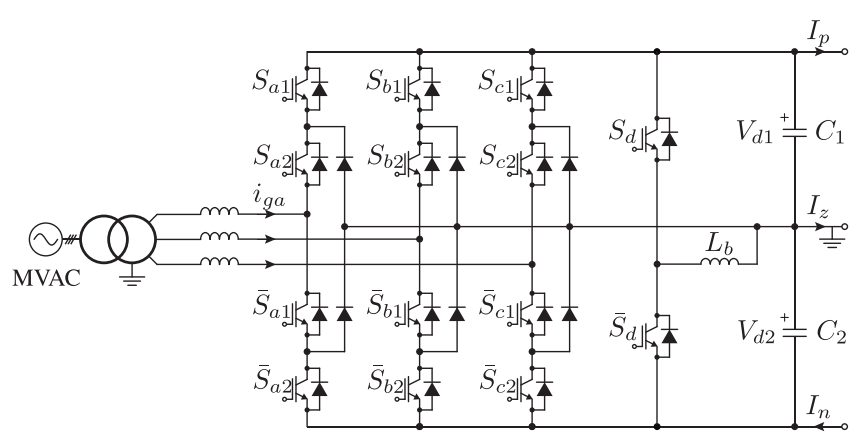

(b)

Figure 8. Different types of dc bipolar grids. (a) $2 \mathrm{~L}-\mathrm{VSC}$ with a buck/boost voltage balancer. (b) $3 \mathrm{~L}-\mathrm{NPC}$ with a buck/boost current redistributor.

\section{Balancing topologies}

One of the main features of the microgrid concept is the inherent flexibility of its structure. Loads and supplies are constantly changing and the converters must adapt their operation accordingly. Considering that, the bipolar dc grid must be conceived as the interaction of several power converters in order to provide a stable operation, being able to handle asymmetrical generation or unbalanced loads [23], [35]. The presence of such stages also provides additional benefits to the system. The main function of these converters is to balance the currents at the dc side, allowing the distribution converter to keep the voltages of the poles balanced to $V_{d} / 2$. By relocating the energy consumption or generation, voltage balancing can be achieved for any operating condition.

Depending on the structure of the dc bus feeding the converters, these additional circuits can be denoted as voltage balancers or current redistributors. However, from the topological point of view, both set of topologies provide the same functionality and can interact with either unipolar or bipolar networks. This is explained in Fig. 8, where a buck stage is employed as a voltage balancer in Fig. 8(a), splitting the dc voltage provided by the $2 \mathrm{~L}-\mathrm{VSC}$. The same converter is acting as a current redistributor in the bipolar bus enabled by the 3L-NPC of Fig. 8(b).

Additional benefits are provided by these stages, as the current redistribution reduces the current flowing through the neutral conductor to virtually zero, thereby the efficiency and stability of the feeder are enhanced [35]. Moreover, balanced operation also eases the implementation and operational requirements of the rectifier stage. The implementation of voltage balancers or current redistributors enable to use offthe-shelf products for the rectifier stage, as there are no special requirements on their operation. Indeed, adding a balancing stage, the rectifier can be used exclusively for the gridconnection related tasks adjusting the power factor, regulating $V_{d}$ and shaping the input currents [35], [37].

Along with all the above mentioned benefits, the presence of these circuits facilitates the connection to ground, thus improving the safety levels in case of remote energy supply by enabling the isolation of the center line.

To perform such corrections, it is mandatory that these stages should provide a bidirectional current handling while having access to both of the dc buses [16].

This section will provide an overview of the main power converter topologies, as well as other non-power-electronicsbased approaches for guaranteeing the independent operation of the dc buses, regardless the load/generation condition.

\section{E. Bidirectional buck-boost topologies}

The circuit in Fig. 8(a) presents the most straight-forward implementation of a regulated bipolar dc bus. This buck-type voltage balancer splits the dc bus voltage $V_{d}$ into $V_{d 1}$ and $V_{d 2}$, while providing an adaptive path for the exceeding currents during unbalanced scenarios [32], [35]. The result is a bipolar network with improved dynamics and two independent buses.

The operational principle of this converter is to regulate the inductor current in such a way that the neutral point is kept balanced. This means that, in case of having different loads in the dc poles, this stage will redistribute the exceeding current and keep the neutral current to its minimal. Considering the input/output relation for this topology, this will be achieved by merely setting the devices duty cycle to 0.5 , however, in order to achieve high performance, a proper inter-pole dynamics modelling and control are required [32]. A similar concept is proposed in [57], were the shoot-through possibility

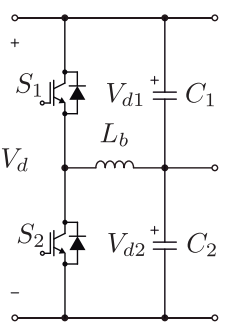

(a)

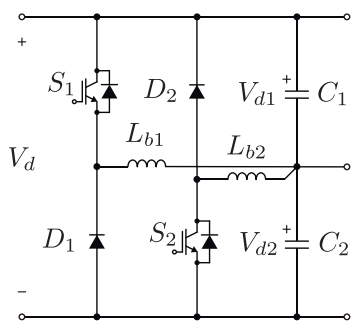

(b)

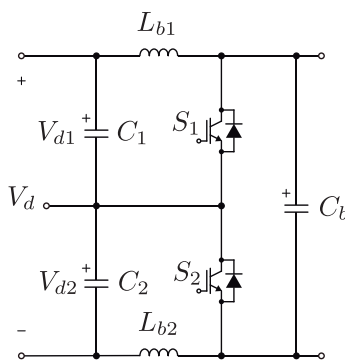

(c)

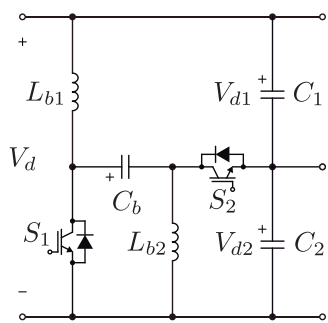

(d)

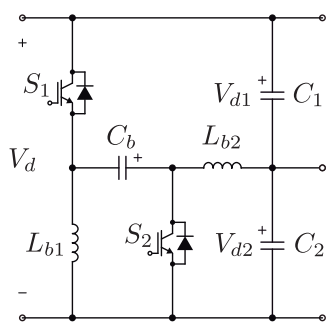

(e)

Figure 9. Bipolar balancer topologies derived from the bidirectional buck/boost concept: (a) buck/boost, (b) dual-buck (c) Cuk, (d) SEPIC and (e) Zeta 


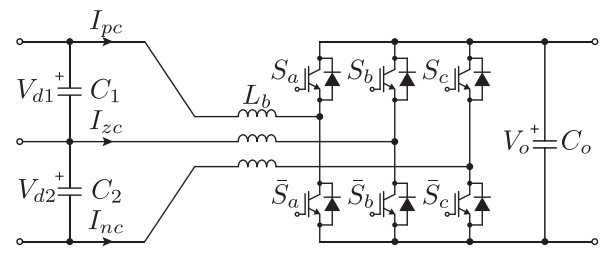

Figure 10. 2L-VSC based current redistributor

is eliminated by using two half-bridge legs and an additional inductor. However, depending on the location of the larger load, only one leg is active to avoid unnecessary losses.

Following this idea, different balancing converters have been developed using conventional $\mathrm{dc}-\mathrm{dc}$ stages as building blocks, either to split the unipolar input voltage, implement bidirectional versions of the basic topology to act as redistributors [38], [58], or multi-channel structures based in simpler converters, in order to improve the performance of the balancing stage [17], [35], [57], [59]. The use of different converter topologies will have a direct impact on the switching devices ratings, efficiency for the intended power, voltage gain, input/output ripples, or passive component count and sizing to name a few. Figure 9 shows different balancing stages based in the most promising dc-dc converters available.

The circuit displayed in Fig. 9(c) is a Cuk-type voltage balancer, which besides providing the regulation of the bipolar bus, it eliminates the shoot-through possibility of the switching devices. In addition, this converter features continuous input and output currents, thus requiring less capacitance values than the buck-based balancer. This comes at the expense of an additional inductor and capacitor, which has to withstand the total dc-link voltage $V_{d}$. Please note that in this case, depending on the location of the imbalance, the dc input and output voltages are the bus voltages, thus the converter will tend to operate with unity voltage gain in steady state. From the implementation point of view, this converter can also be assembled with off-the-shelf half-bridge modules, which is beneficial as well.

Following the same concept, SEPIC- and Zeta-type voltage balancers have also been reported [38], [58], which are displayed in Figures 9(d) and 9(e) respectively. By replacing the conventional diode in these high-order topologies, a bidirectional current path is enabled, allowing the converter to regulate the bus voltages regardless the location of the imbalance and also eliminate the risk of shoot-through of the dc grid. Considering that in these cases, the input voltage becomes the total de voltage $V_{d}$, the duty cycle will tend to $1 / 3$ when balance is reached. Consequently, these balancers require a coupling capacitor with higher voltage ratings, and the switching devices will block $3 V_{d} / 2$. Also, their asymmetrical structure results in different current ratings for the inductors and the switches.

As discussed earlier, another approach for enhancing the voltage balancing stage is to use additional channels and operate them interleaved, reducing the rated current handled by each channel. This connection will improve the output ripple characteristics, leading to a reduction in the inductances

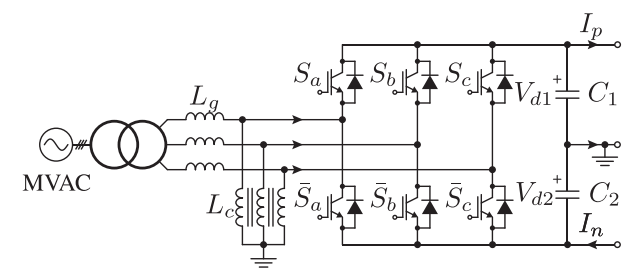

Figure 11. 2L-VSC with a grounding inductor balancer

and capacitance values [38]. This leads to a smoother output current, which allows the reduction in the output inductor by a factor of $1 / \mathrm{n}$, for an $\mathrm{n}$-channel converter [44].

The circuit in Fig. 10 can also serve towards the power balance of the buses. The topology proposed in [35] regulates the positive and negative bar currents in such a way that the neutral current $I_{z c}$ is almost zero. However, this is not sufficient to guarantee a stable operation, as the exceeding power must be relocated to the opposite pole and returned to the grid. The result is a control scheme based on the sum-difference domain, that ensures balance for asymmetrical operation in split-dc networks. The fact that this current redistributor is based in the conventional 2L-VSC, facilitates its implementation using commercially available six-pack IGBT/MOSFET modules. This feature also applies to the buck/boost balancer, as one module can serve as a three-channel balancing stage.

\section{F. Coupled inductor current redistributor}

A similar approach to the concept in Fig. 5 is proposed in [48], where by the means of a grounding reactor a current injection path is created between the ac and dc neutral points. This current redistributor is shown in Fig. 11. Considering the application, its main function is the regulation of the zero-sequence dc current when imbalances arises. However, it must also maintain a reduced amplitude of the ac currents. Then, through a careful design of the grounding inductor, the efficiency of this balancer is maintained. Also, in order to reduce the saturation risk caused by the dc flux, the topology features a coupled magnetic core.

This core is designed in order to generate zero-sequence inductances that are substantially lower than the ac ones. The latter ones are desired to have large values, in order to reduce the sustained ac currents. The structure of the inductor enables a viable path for the returning dc currents, enhancing the controllability of the distribution system and passively regulating the dc bus voltages regardless the load condition. This approach offers a trade-off between having less power electronics and increasing the magnetic losses.

\section{G. Three-port current redistributor}

The converter proposed in [60] is shown in Fig. 12a. The topology consists in two half-bridges with a coupled inductor, which under balanced scenarios, it will operate as two independent buck/boost converters by synchronizing the operation of the outer switches and the inner ones. However, when imbalances arise, the introduction of a phase shift between these pair of switches, will increase the current flowing 


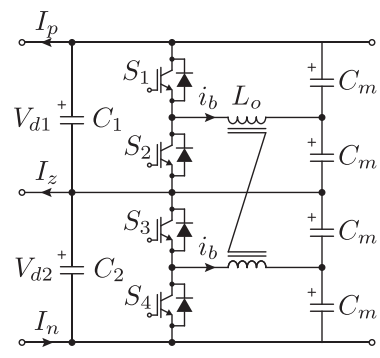

(a)

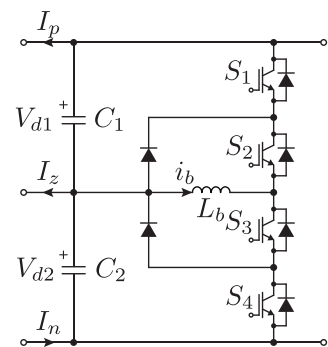

(b)

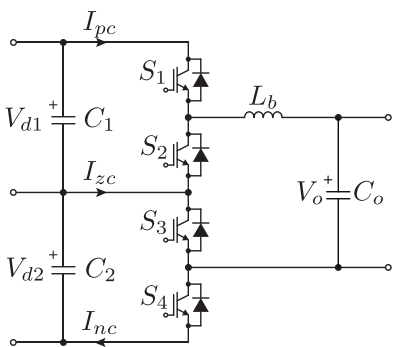

(c)

Figure 12. Current redistributing topologies: (a) Three-port current redistributior, (b) 3L-NPC balancer and (c) three-level buck/boost

through the coupled inductor, enabling the power transfer between the dc buses. Note that the switches of both channels have the same duty cycle, generated by a current controller similar to the one employed in a conventional buck, and the phase displacement between the phases is the responsible for the power exchange, similar to the operational principle of the dual active bridge.

\section{H. Three-level $d c-d c$ current redistributors}

The three-wire structure of the bipolar dc grids, makes the three-level based topologies a natural decision. Similar to the case of using the 3L-NPC as the distribution converter, threelevel based dc-dc stages can be easily applied as voltage balancers or current redistributors. The fundamental limitation that the 3L-NPC converter has for driving current through its neutral conductor motivated the scheme in [15]. The basic idea was to use an additional NPC leg as a buck/boost stage, that redirects the exceeding neutral point current to the unloaded terminal in order to assist the distribution NPC in the balancing tasks. The structure allows to handle any load condition in the buses, but also offers the trade-off between minimizing the current stress in the dc inductor or alleviate the distribution converter from the balancing tasks in order to enhance the grid-side quantities.

A different scheme is proposed in [37], where this 3L-NPC leg is modulated differently, including free-wheeling times that rearranges the exceeding current and keeps the midpoint voltage regulated. The idea is the following, when asymmetrical power consumption exists, the modulator takes the exceeding current from the bus lightly loaded and supplies it to the other bus through the dc inductor.

The works in [17], [56], [61] use a different three-level dcdc converter for feeding high-power loads and also contribute to minimize power fluctuations in bipolar dc systems. The power circuit is presented in Figure 12(c), where it can be seen that the basic unit is composed by four switching devices and their corresponding free-wheeling diodes, along with an output inductor and the output filter capacitor. Depending on the power level, more units can be connected in interleaved configuration to minimize current stress in the switches and inductors [17].

One bipolar application of the aforementioned topology is interfacing an ESS [56]. By replacing the additional balancing leg, this converter allows to accomplish two simultaneous objectives: the main one is to perform the charge and discharge of the storage element according to the energy management supervisor controller of the dc network, but at the same time uses this process to relocate the power consumption at dc level and complement the balancing task performed by the distribution converter. Given the nature of the topology, the system is able to guarantee stable operation with an ESS with reduced power ratings.

When feeding high-power loads, the converter in Fig. 12(c) can be configured interleaved in order to minimize the stress in the dc inductors. In [17], these stages offer the possibility of either assist the central converter in the balance, or exclusively take this task in a distributed manner. The same concept is further studied when using coupled inductors in order to enhance the current profile in the dc-dc stage [59].

Additionally, the three-level buck/boost converter exhibited in Fig. 12(b) is also able to generate two independent poles from a unipolar voltage as suggested in [62], [63], despite is intended for PV and wind generation systems, the functionality provided by this topology is also suitable for dc bipolar grids.

A comparative chart is presented in Table II between the different balancing stages allows to establish which topology suits more to each case. In order to establish a fair comparison between the different balancers, the following scenario is simulated: a bipolar system of $\pm 350 \mathrm{~V}$ is feeding a rated load of $17.5 \mathrm{~kW}$ connected in the upper bus. The inductance and capacitance values are kept the same for all the topologies, while the equivalent switching frequency is also kept constant. In order to provide a fair comparison, the total average switching device power (SDP) is provided. The average SDP is calculated as follows [64]:

$$
\mathrm{SDP}_{\mathrm{avg}}=\sum_{i=1}^{N} V_{i} \bar{I}_{i},
$$

where $V_{i}$ is the voltage stress for the $i$-th device and $\bar{I}_{i}$ is its average current. All the simulations were carried out using using PLECS $\AA$. Overall, the multilevel-based configurations allow to reduce the voltage stress in the devices and improve the ripple characteristics, which enhances their EMI compatibility, while featuring a larger device count. On the other hand, the buck/boost balancer represents the most simple and cost-effective way of implementing a balancing structure, at the expenses of a larger voltage stress on the devices, as they have to withstand the total de voltage $V_{d}$. Among the high- 
Table II

COMPARISON OF VOLTAGE BALANCERS AND DISTRIBUTORS ${ }^{1}$

\begin{tabular}{|c|c|c|c|c|c|c|c|}
\hline Balancing Topology & Inductors & Caps & Switches & $\begin{array}{c}\text { Sw. Voltage } \\
\text { Stress } \\
\end{array}$ & $\begin{array}{c}\text { Ind. Avgerage } \\
\text { Current }\end{array}$ & $\begin{array}{c}\text { Current } \\
\text { Ripple } \mathbf{p u}^{2}\end{array}$ & $\begin{array}{c}\text { Total } \\
\text { SDP }_{\text {avg }} \\
\end{array}$ \\
\hline Buck/Boost Fig. 9(a) & $\overline{1}$ & $\overline{2}$ & $\overline{2}$ & $\overline{\overline{V_{d}}}$ & $\overline{I_{d 1}}$ & 0.25 & $2 P_{d 1}$ \\
\hline Dual Buck Fig. 9(b) & 2 & 2 & 4 & $V_{d}$ & $I_{d 1}$ & 0.25 & $2 P_{d 1}$ \\
\hline Cuk Fig. 9(c) & 2 & 3 & 2 & $V_{d}$ & $0.5 I_{d 1}$ & 0.25 & $2 P_{d 1}$ \\
\hline SEPIC Fig. 9(d) & 2 & 3 & 2 & $1.5 V_{d}$ & $0.5 I_{d 1}, I_{d 1}$ & $0 . \overline{3}$ & $4.5 P_{d 1}$ \\
\hline Zeta Fig. 9(e) & 2 & 3 & 2 & $1.5 V_{d}$ & $I_{d 1}, 0.5 I_{d 1}$ & $0 . \overline{3}$ & $4.5 P_{d 1}$ \\
\hline 2L-VSC ${ }^{3}$ Fig. 10 & 3 & 3 & 6 & $V_{d} / d_{o}$ & $I_{d 1}, 0.5 I_{d 1}, 0.5 I_{d 1}$ & $0 . \overline{3}$ & $6 P_{d 1}$ \\
\hline 3L-NPC ${ }^{4}$ Fig. 12(b) & 1 & 2 & 6 & $0.5 V_{d}$ & $0.5 I_{d 1} / d_{u}$ & $0.5 d_{u}$ & $P_{d 1} / d_{u}$ \\
\hline 3L-Buck/Boost ${ }^{3}$ Fig. 12(c) & 1 & 2 & 4 & $0.5 V_{d}$ & $I_{d 1} / d_{i}$ & $d_{i}\left(1-d_{i}\right)$ & $2 P_{d 1} / d_{i}$ \\
\hline \multicolumn{8}{|c|}{$\begin{array}{l}\text { 1. The comparison is made considering that lower dc bus is unloaded while the upper one remains at rated power } P_{d 1}=0.5 V_{d} I_{d 1} \text {. } \\
\text { 2. The listed values are normalized with the ratio } V_{d} /\left(f_{\mathrm{sw}} L_{b}\right) \text {. } \\
\text { 3. These topologies require an additional output to redistribute current, whose voltage is given by } V_{o}=V_{d} / d_{o} \text { and } V_{o}=0.5 d_{i} V_{d} \text {., respectively } \\
\text { 4. The duty cycle for the outer switches } d_{u} \text { allows to incorporate free-wheeling times, which reduce the inductor current ripple but increase } \\
\text { its average current. }\end{array}$} \\
\hline
\end{tabular}

Table III

OVERVIEW OF Voltage BALANCER FEATURES

\begin{tabular}{|c|c|c|}
\hline Balancing Topology & Advantages & Drawbacks \\
\hline$\overline{\overline{\text { Buck/Boost Fig. 9(a) }}}$ & $\begin{array}{l}\text { - Minimun component count. } \\
\text { - Simple and cost-effective implementation. } \\
\text { - Easy multichannel operation. }\end{array}$ & $\begin{array}{l}\text { - Large filter size and EMI issues. } \\
\text { - Low efficiency for high voltage gain operation. }\end{array}$ \\
\hline Dual Buck Fig. 9(b) & $\begin{array}{l}\text { - No shoot-through concerns. } \\
\text { - No dead time required. }\end{array}$ & $\begin{array}{l}\text { - Magnetic components affect volume and cost. } \\
\text { - Slow dynamic response. }\end{array}$ \\
\hline Cuk Fig. 9(c) & $\begin{array}{l}\text { - No shoot-through concerns. } \\
\text { - Continuous input and output currents. }\end{array}$ & $\begin{array}{l}\text { - High number of reactive components. } \\
\text { - Expensive solution at larger powers }(>5 \mathrm{~kW}) \text {. }\end{array}$ \\
\hline SEPIC Fig. 9(d) & $\begin{array}{l}\text { - High-order converter. } \\
\text { - Reduced switching device count. }\end{array}$ & $\begin{array}{l}\text { - Large capacitor with high current stress. } \\
\text { - Higher blocking voltage }(150 \%) \text { for switches. }\end{array}$ \\
\hline Zeta Fig. 9(e) & $\begin{array}{l}\text { - All zeros are minimun phase. } \\
\text { - No shoot-through concerns. }\end{array}$ & $\begin{array}{l}\text { - High voltage stress for switching devices }(150 \%) \text {. } \\
\text { - Reduced power range. }\end{array}$ \\
\hline 2L-VSC Fig. 10 & $\begin{array}{l}\text { - Standard and easy implementation through PEBB. } \\
\text { - Improves system stability and reliability. }\end{array}$ & $\begin{array}{l}\text { - Large device and component count. } \\
\text { - Requires an additional load to relocate power. }\end{array}$ \\
\hline 3L-NPC Fig. 12(b) & $\begin{array}{l}\text { - Standard and easy implementation through PEBB. } \\
\text { - High-power ready. } \\
\text { - Reduced voltage stress. }\end{array}$ & $\begin{array}{l}\text { - Large device count. } \\
\text { - Trade-off between reduced inductor current ripple } \\
\text { and average current. }\end{array}$ \\
\hline 3L-Buck/Boost Fig. 12(c) & $\begin{array}{l}\text { - Reduced voltage stress for switches } \\
\text { - Wide power range. } \\
\text { - Can be sized with reduced power rating. }\end{array}$ & $\begin{array}{l}\text { - Large device count. } \\
\text { - Requires a dedicated ESS to compensate imbal- } \\
\text { ances. }\end{array}$ \\
\hline
\end{tabular}

order converter stages, Cuk balancer stands out, as it maintains the same SDP for the buck/boost balancer, while reducing the average current value in the inductors to half, which is compensated by the additional passive component count.

For further information, Table III resumes the findings highlighting the benefits and drawbacks of each balancing unit. As expected, there is no clear candidate for performing the balancing tasks, as the features and performance offered by each stage will depend strongly on the voltage and power range intended.

\section{Summary AND Future TREnds}

The recent growth of dc systems is the result of a convergence of needs originated in different sectors: renewable energy conversion, information technology and transportation. This has resulted in a growing presence of dc nature structures in both transmission and distribution levels, offering highperformance solutions with enhanced efficiency and reliability, besides reducing the number of power conversion stages involved and uninterrupted power delivery. Several converters have been proposed for both, integrating these networks to conventional ac grids, and also guarantee the decoupling of the buses regardless the load condition. However, none of the above solutions presents clear advantages for LVDC networks, as their performance and features are strongly dependent on the intended voltage and power range. On the other hand, the remarkable performance offered by wide band gap devices has lead to substantial improvements in power converters, allowing to reach unprecedented efficiency levels, $\mathrm{SiC}$ and $\mathrm{GaN}$ devices hold the potential to bring the losses to a marginal level. In the remainder of the section a brief discussion on recent topologies enabled by these devices will be presented, focusing on their attractiveness and suitability for bipolar LVDC grids.

Direct-current distributed data centers may only include storage stages besides the grid-tied converter, with no local generation, thereby a bidirectional path for the input current may not be strictly needed. Pointing in this direction, several modern active rectifiers have been developed or improved as presented in Fig. 13. Among these rectifiers, is the Vienna Rectifier (VR) [65]-[67]. This topology shares the operating principle of stepping up the voltage and a three-level voltage waveform with the $3 \mathrm{~L}-\mathrm{NPC}$, besides enabling a bipolar dc 


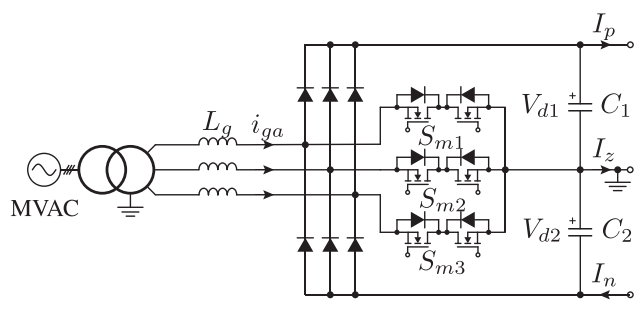

(a)

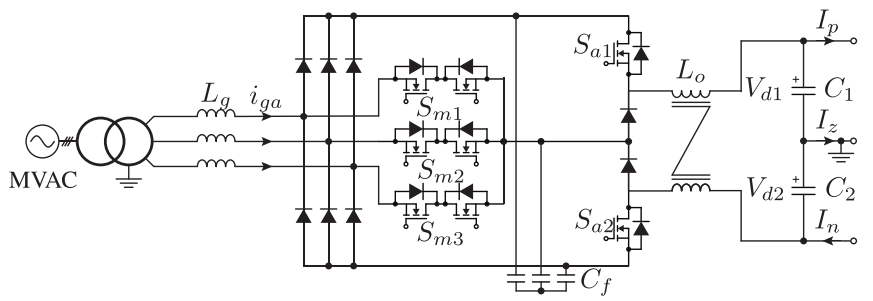

(c)

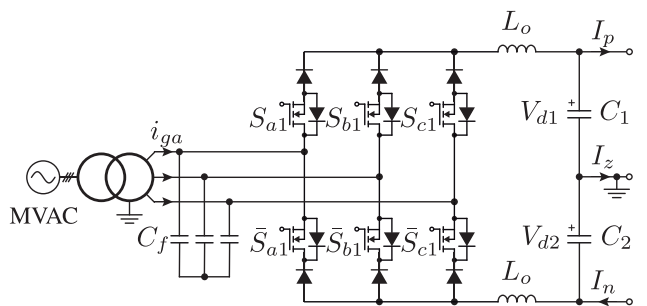

(b)

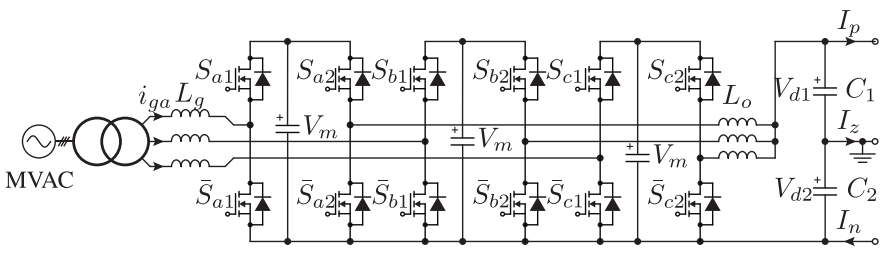

(d)

Figure 13. Modern Active Rectifiers: (a) Vienna Rectifier. (b) SWISS Rectifier. (c) Three-phase Buck Rectifier. (d) Phase-Modular converter.

output with room for unbalanced operation [68], [69]. However, it features a lower active switching devices count as displayed in Fig. 13(a). Recent developments on MOSFET switching devices, allowed this converter to reach extremely high efficiencies even when switching at $1 \mathrm{MHz}$ [70]. Results in the mentioned work reached $96 \%$ for a $10 \mathrm{~kW}$ converter, which is within the range of modern LVDC grids. Besides the conventional boost feature of the majority of modern rectifiers, a buck-type family has been developed lately, being able to directly integrate $400-\mathrm{V}$ dc systems to $230 \mathrm{~V}$ ac grids with sinusoidal input currents, with no additional stages or transformers. With this in mind, the circuit in Fig. 13(b) has been proposed for high-performance LVDC systems. By adding a power MOSFET in series to each diode of a passive rectifier, the Buck-Type PFC Rectifier is conceived [6]. This solution reaches $98.9 \%$ efficiency for a $400 \mathrm{~V}$ output [71], through an appropriate semiconductor effort. Another possibility is the SWISS Rectifier, presented in Fig. 13(c). This converter features sinusoidal input currents besides a buck feature, with virtually no losses reaching a peak efficiency of $99.26 \%$ [10].

Another recent concept for a bidirectional rectifier is shown in Fig. 13(d). It can be seen that results from the combination of three independently controlled boost-buck stages [72]. Considering this, the intermediate dc-link voltages $V_{m}$ have to be controlled to be at least twice the ac voltage amplitude, similar to a single-phase rectifier, in order to be able to generate the high-quality input current. According to the study, this concept potentially can reduce the overall losses by $27 \%$ while keeping the same power density of the conventional solutions.

Finally, considering exceptional efficiencies are driving the development of LVDC systems, the idea of having a converter that provides the same functionality of a full-rated converter, but only incurring in a fraction of the losses is being applied in different areas [7], [8], [73], [74]. The work in [75] introduces a dual active bridge as a partial power-flow regulator, then [76] extends it to bipolar grids, in order to keep the voltages from

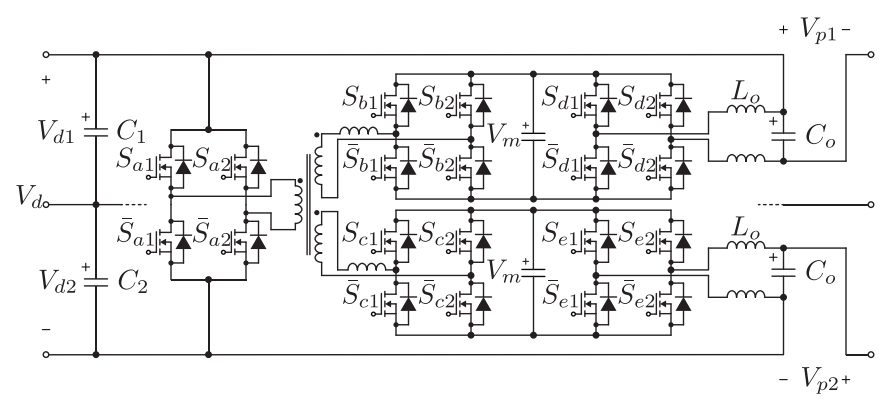

Figure 14. Partially Rated TAB Power Flow Converter.

drifting in a bipolar-meshed dc grid, as shown in Fig. 14.

\section{CONClusion}

Two kinds of architectures are possible for implementing LVDC networks: unipolar and bipolar. Despite being a more sophisticated and technically complex solution, bipolar structures can offer several advantages over conventional unipolar ones when properly regulated. Higher availability, efficiency and flexibility are just a few advantages featured by bipolar systems.

On the other hand, bipolar grid has certain similarities with a conventional three-phase ac system, where the phase voltage in an ac system is the analogue to the voltage between one pole and the neutral point in the bipolar LVDC grid, and the lineto-line ac voltage can be considered as the voltage between the positive and negative poles of the bipolar LVDC grid. This resemblance with ac systems is beneficial for the operation, retrofitting and also for developing the control schemes.

These features will only be achieved if the three-wire structure could guarantee a stable asymmetrical operation. This is because there is a dependency between the poles and this uneven power distribution can be problematic if not taken care 
properly. The main issues are the dc-voltage drift, higher losses and a decreased power quality of the system.

Given the limited capability of the distribution converter, additional circuitry is required to overcome the presence of unbalanced power. Voltage balancers and/or current redistributors are essential to deal with asymmetrical operation, allowing to keep the system in a balanced and stable operation. As it was discussed in the paper, the converter topologies employed in bipolar LVDC systems need to be bidirectional, in order to allow the reversible power flow given the flexible structure of distributed networks.

Recent advances show a bright future for LVDC systems, and bipolar grids should play a fundamental role. The main contribution of this survey are the following:

- A complete discussion on the main converter topologies involved in bipolar LVDC networks, comparing their features and drawbacks.

- An exhaustive review and fair comparison of the different topologies involved in the voltage balancing and current regulation tasks, in order to highlight their benefits and limitations.

- The introduction of selected topologies that could further enhance the benefits of these systems.

- A regulatory set of requirements is presented and discussed, in order to clear some misconceptions and older beliefs regarding the challenges in safety for dc networks.

- Additionally, the availability of regulation standards supports the development of new solutions that will perform accordingly when implemented in real systems.

\section{ACKNOWLEDGEMENT}

The authors acknowledge the support provided by the following ANID projects: FONDECYT Iniciación 11170774 , REDES-PCI 170213, AC3E (ANID-Basal Project FB0008) and SERC Chile (ANID/FONDAP/15110019). Also, this work was supported in part by UCSC under the internal project no. FIATEC 01-2019-UCSC.

\section{REFERENCES}

[1] T. Dragičević, X. Lu, J. C. Vasquez, and J. M. Guerrero, "DC Microgrids-Part I: A Review of Control Strategies and Stabilization Techniques," IEEE Trans. Power Electron., vol. 31, no. 7, pp. 48764891, July 2016.

[2] E. Rodriguez-Diaz, F. Chen, J. C. Vasquez, J. M. Guerrero, R. Burgos, and D. Boroyevich, "Voltage-level selection of future two-level lvdc distribution grids: A compromise between grid compatibiliy, safety, and efficiency," IEEE Electrification Magazine, vol. 4, no. 2, pp. 20-28, June 2016.

[3] D. Boroyevich, I. Cvetkovic, R. Burgos, and D. Dong, "Intergrid: A future electronic energy network?" IEEE Trans. Emerg. Sel. Topics Power Electron., vol. 1, no. 3, pp. 127-138, Sep. 2013.

[4] T. Dragičević, J. C. Vasquez, J. M. Guerrero, and D. Skrlec, "Advanced LVDC Electrical Power Architectures and Microgrids: A step toward a new generation of power distribution networks." IEEE Electrific. Mag., vol. 2, no. 1, pp. 54-65, March 2014.

[5] L. E. Zubieta, "Are Microgrids the Future of Energy?: DC Microgrids from Concept to Demonstration to Deployment," IEEE Electrification Magazine, vol. 4, no. 2, pp. 37-44, June 2016.

[6] A. Stupar, T. Friedli, J. Minibock, and J. W. Kolar, "Towards a 99\% Efficient Three-Phase Buck-Type PFC Rectifier for 400-V DC Distribution Systems," IEEE Trans. Power Electron., vol. 27, no. 4, pp. 1732-1744, April 2012.
[7] E. Candan, P. S. Shenoy, and R. C. N. Pilawa-Podgurski, "A seriesstacked power delivery architecture with isolated differential power conversion for data centers," IEEE Trans. Power Electron., vol. 31, no. 5, pp. 3690-3703, May 2016.

[8] E. Candan, D. Heeger, P. S. Shenoy, and R. C. N. Pilawa-Podgurski, "Hot-swapping analysis and implementation of series-stacked server power delivery architectures," IEEE Trans. Power Electron., vol. 32, no. 10, pp. 8071-8088, Oct 2017.

[9] L. Schrittwieser, J. W. Kolar, and T. B. Soeiro, "99\% Efficient ThreePhase Buck-Type SiC MOSFET PFC Rectifier Minimizing Life Cycle Cost in DC Data Centers," CPSS Transactions on Power Electronics and Applications, vol. 2, no. 1, pp. 47-58, 2017.

[10] L. Schrittwieser, M. Leibl, M. Haider, F. Thöny, J. W. Kolar, and T. B. Soeiro, "99.3\% Efficient Three-Phase Buck-Type All-SiC SWISS Rectifier for DC Distribution Systems," IEEE Trans. Power Electron., vol. 34, no. 1, pp. 126-140, Jan 2019.

[11] L. Dickerman and J. Harrison, "A new car, a new grid," IEEE Power and Energy Magazine, vol. 8, no. 2, pp. 55-61, March 2010.

[12] S. Dusmez, A. Cook, and A. Khaligh, "Comprehensive Analysis of High Quality Power Converters for Level 3 Off-Board Chargers," in 2011 IEEE Vehicle Power and Propulsion Conference, Sept 2011, pp. 1-10.

[13] A. Khaligh and S. Dusmez, "Comprehensive Topological Analysis of Conductive and Inductive Charging Solutions for Plug-In Electric Vehicles," IEEE Trans. Veh. Technol., vol. 61, no. 8, pp. 3475-3489, Oct 2012 .

[14] S. Bai and S. M. Lukic, "Unified active filter and energy storage system for an mw electric vehicle charging station," IEEE Trans. Power Electron., vol. 28, no. 12, pp. 5793-5803, Dec 2013.

[15] S. Rivera, B. Wu, S. Kouro, V. Yaramasu, and J. Wang, "Electric Vehicle Charging Station using a Neutral Point Clamped Converter with Bipolar DC Bus," IEEE Trans. Ind. Electron., vol. 62, no. 4, pp. 1999-2009, April 2015.

[16] S. Rivera and B. Wu, "Electric Vehicle Charging Station With an Energy Storage Stage for Split-DC Bus Voltage Balancing," IEEE Trans. Power Electron., vol. 32, no. 3, pp. 2376-2386, March 2017.

[17] L. Tan, B. Wu, S. Rivera, and V. Yaramasu, "Comprehensive DC Power Balance Management in High-Power Three-Level DC-DC Converter for Electric Vehicle Fast Charging," IEEE Trans. Power Electron., vol. 31, no. 1, pp. 89-100, Jan 2016.

[18] E. Rosales-Asensio, M. de Simón-Martín, D. Borge-Diez, J. J. Blanes-Peiró, and A. Colmenar-Santos, "Microgrids with energy storage systems as a means to increase power resilience: An application to office buildings," Energy, vol. 172, pp. 1005 - 1015, 2019. [Online]. Available: http://www.sciencedirect.com/science/article/pii/S0360544219302324

[19] R. K. Chauhan, C. Phurailatpam, B. S. Rajpurohit, F. M. GonzalezLongatt, and S. N. Singh, "Demand-side management system for autonomous dc microgrid for building," Technology and Economics of Smart Grids and Sustainable Energy, vol. 2, no. 1, p. 4, Feb 2017. [Online]. Available: https://doi.org/10.1007/s40866-017-0020-y

[20] D. L. Gerber, "A simulation-based efficiency comparison of ac and dc power distribution networks in commercial buildings," Applied energy, vol. v. 210, pp. pp. 21-1187-2018 v.210, 2018.

[21] V. Vossos, D. Gerber, Y. Bennani, R. Brown, and C. Marnay, "Technoeconomic analysis of dc power distribution in commercial buildings," Applied Energy, vol. 230, pp. 663 - 678, 2018. [Online]. Available: http://www.sciencedirect.com/science/article/pii/S0306261918312339

[22] D. Salomonsson, "Modeling, Control and Protection of Low-Voltage DC Microgrids," Ph.D. dissertation, Royal Institute of Technology, Sweden, Apr. 2009.

[23] S. Rivera, R. Lizana, S. Kouro, and B. Wu, Bipolar-Type DC Microgrids for High-Quality Power Distribution, ser. Energy Engineering. Institution of Engineering and Technology, 2018, pp. 245-266. [Online]. Available: https://digital-library.theiet.org/content/books/10. 1049/pbpo115e_ch10

[24] H. Kakigano, Y. Miura, and T. Ise, "Distribution Voltage Control for DC Microgrids Using Fuzzy Control and Gain-Scheduling Technique," IEEE Trans. Power Electron., vol. 28, no. 5, pp. 2246-2258, May 2013.

[25] — , "Low-Voltage Bipolar-Type DC Microgrid for Super High Quality Distribution," IEEE Trans. Power Electron., vol. 25, no. 12, pp. 30663075, Dec. 2010.

[26] D. Salomonsson and A. Sannino, "Low-Voltage DC Distribution System for Commercial Power Systems With Sensitive Electronic Loads," IEEE Trans. Power Del., vol. 22, no. 3, pp. 1620-1627, July 2007.

[27] "DIRECTIVE 2014/35/EU OF THE EUROPEAN PARLIAMENT AND OF THE COUNCIL of 26 February 2014 on the harmonisation of the laws of the Member States relating to the making available on the market of electrical equipment designed for use within certain voltage limits 
(recast)(Text with EEA relevance)," Official Journal of the European Union, vol. L 96, pp. 357-374, Mar 2014.

[28] “NPR 9090:2018 NL: DC Installations for Low Voltage," Royal Dutch Standardization Institute (NEN), pp. 1-50, Sep 2018.

[29] "Low-Voltage Electrical Installations," International Electrotechnical Commission, Standard IEC 60364-1:2005, 2014. [Online]. Available: https://webstore.iec.ch/publication/1865

[30] T. Dragičević, X. Lu, J. C. Vasquez, and J. M. Guerrero, "DC Microgrids - Part II: A Review of Power Architectures, Applications, and Standardization Issues," IEEE Trans. Power Electron., vol. 31, no. 5, pp. 3528-3549, May 2016.

[31] T. Kaipia, P. Salonen, J. Lassila, and J. Partanen, "Possibilities of the Low Voltage DC Distribution Systems," in Nordic Distribu. and Asset Manag. Conference (NORDAC), Stockholm, Sweden, Aug. 2006.

[32] Y. Gu, W. Li, and X. He, "Analysis and Control of Bipolar LVDC Grid With DC Symmetrical Component Method," IEEE Trans. Power Syst., vol. 31, no. 1, pp. 685-694, Jan 2016.

[33] H. Kakigano, Y. Miura, T. Ise, and R. Uchida, "DC Voltage Control of the DC Micro-grid for Super High Quality Distribution," in Power Conversion Conference - Nagoya, 2007. PCC '07, 2007, pp. 518-525.

[34] B.-M. Han, "A Half-Bridge Voltage Balancer with New Controller for Bipolar DC Distribution Systems," Energies, vol. 9, no. 3: 182, 2016.

[35] J. Lago and M. L. Heldwein, "Operation and control-oriented modeling of a power converter for current balancing and stability improvement of dc active distribution networks," IEEE Trans. Power Electron., vol. 26, no. 3, pp. 877-885, March 2011 .

[36] J. Lago, J. Moia, and M. L. Heldwein, "Evaluation of power converters to implement bipolar DC active distribution networks - DC-DC converters," in 2011 IEEE Energy Conversion Congr. and Expo. (ECCE), Sept 2011, pp. 985-990.

[37] X. Zhang, C. Gong, and Z. Yao, "Three-Level DC Converter for Balancing DC 800-V Voltage," IEEE Trans. Power Electron., vol. 30, no. 7, pp. 3499-3507, July 2015.

[38] F. Wang, Z. Lei, X. Xu, and X. Shu, "Topology Deduction and Analysis of Voltage Balancers for DC Microgrid," IEEE Trans. Emerg. Sel. Topics Power Electron., vol. 5, no. 2, pp. 672-680, June 2017.

[39] E. Rodriguez-Diaz, M. Savaghebi, J. C. Vasquez, and J. M. Guerrero, "An overview of low voltage DC distribution systems for residential applications," in 2015 IEEE 5th International Conference on Consumer Electronics - Berlin (ICCE-Berlin), Sept 2015, pp. 318-322.

[40] E. Vossos, "Optimizing Energy Savings from Direct-DC in U.S. Residential Buildings," Ph.D. dissertation, San Jose State University, San Jose, California, USA, Aug. 2011.

[41] D. Salomonsson, L. Soder, and A. Sannino, "Protection of low-voltage dc microgrids," IEEE Transactions on Power Delivery, vol. 24, no. 3, pp. 1045-1053, July 2009.

[42] J. Mohammadi, F. Badrkhani Ajaei, and G. Stevens, "Grounding the dc microgrid," IEEE Transactions on Industry Applications, vol. 55, no. 5, pp. 4490-4499, Sep. 2019.

[43] J. Moia, J. Lago, A. Perin, and M. Heldwein, "Comparison of ThreePhase PWM Rectifiers to Interface AC Grids and Bipolar DC Active Distribution Networks," in Power Electron. for Distributed Generation Syst. (PEDG), 2012 3rd IEEE Int. Symp. on, 2012, pp. 221-228.

[44] S. Rivera, S. Kouro, and B. Wu, Charging Architectures for Electric and Plug-In Hybrid Electric Vehicles. Basel, Switzerland: Springer International Publishing, 2017, pp. 111-149. [Online]. Available: http://dx.doi.org/10.1007/978-3-319-43651-7_4

[45] J. W. A. Wilson, "The forced-commutated inverter as a regenerative rectifier," IEEE Trans. Ind. Appl., vol. IA-14, no. 4, pp. 335 -340, Jul. 1978.

[46] D. Dong, F. Luo, X. Zhang, D. Boroyevich, and P. Mattavelli, "Gridinterface bidirectional converter for residential dc distribution systems-part 2: Ac and dc interface design with passive components minimization," IEEE Trans. Power Electron., vol. 28, no. 4, pp. 16671679, April 2013.

[47] T. H. Jung, G. H. Gwon, C. H. Kim, J. Han, Y. S. Oh, and C. H Noh, "Voltage Regulation Method for Voltage Drop Compensation and Unbalance Reduction in Bipolar Low-Voltage DC Distribution System," IEEE Trans. Power Del., vol. 33, no. 1, pp. 141-149, Feb 2018.

[48] Y. Li, A. Junyent-Ferré, and J. M. Rodriguez-Bernuz, "A Three-Phase Active Rectifier Topology for Bipolar DC Distribution," IEEE Trans. Power Electron., vol. 33, no. 2, pp. 1063-1074, Feb 2018.

[49] A. Lana, P. Nuutinen, J. Karppanen, P. Peltoniemi, T. Kaipia, and J. Partanen, "Control of directly connected energy storage in lvdc distribution network," in 11th IET International Conference on AC and DC Power Transmission, Feb 2015, pp. 1-6.
[50] P. Nuutinen, T. Kaipia, P. Peltoniemi, A. Lana, A. Pinomaa, A. Mattsson, P. Silventoinen, J. Partanen, J. Lohjala, and M. Matikainen, "Research site for low-voltage direct current distribution in a utility network-structure, functions, and operation," IEEE Transactions on Smart Grid, vol. 5, no. 5, pp. 2574-2582, Sep. 2014.

[51] P. Nuutinen, A. Pinomaa, P. Peltoniemi, T. Kaipia, J. Karppanen, and P. Silventoinen, "Common-mode and rf emi in a low-voltage dc distribution network with a pwm grid-tie rectifying converter," IEEE Transactions on Smart Grid, vol. 8, no. 1, pp. 400-408, Jan 2017.

[52] S. Kouro, M. Malinowski, K. Gopakumar, J. Pou, L. G. Franquelo, B. Wu, J. Rodriguez, M. A. Perez, and J. I. Leon, "Recent Advances and Industrial Applications of Multilevel Converters," IEEE Trans. Ind. Electron., vol. 57, no. 8, pp. 2553 -2580, Aug. 2010.

[53] N. Celanovic and D. Boroyevich, "A Comprehensive Study of NeutralPoint Voltage Balancing Problem in Three-Level Neutral-Point-Clamped Voltage Source PWM Inverters," IEEE Trans. Power Electron., vol. 15 , no. 2, pp. 242-249, Mar 2000.

[54] A. Yazdani and R. Iravani, "A Generalized State-Space Averaged Model of the Three-Level NPC Converter for Systematic DC-Voltage-Balancer and Current-Controller Design," IEEE Trans. Power Del., vol. 20, no. 2, pp. 1105-1114, Apr. 2005.

[55] Z. Mohzani, B. P. McGrath, and D. G. Holmes, "The Balancing Properties of DC Link Compensation for 3-phase Neutral Point Clamped (NPC) Converter," in Proceedings of The 7th International Power Electronics and Motion Control Conference, vol. 1, June 2012, pp. 574-579.

[56] L. Tan, B. Wu, V. Yaramasu, S. Rivera, and X. Guo, "Effective Voltage Balance Control for Bipolar-DC-Bus-Fed EV Charging Station With Three-Level DC-DC Fast Charger," IEEE Trans. Ind. Electron., vol. 63, no. 7, pp. 4031-4041, July 2016.

[57] X. Zhang and C. Gong, "Dual-buck half-bridge voltage balancer," IEEE Trans. Ind. Electron., vol. 60, no. 8, pp. 3157-3164, Aug 2013.

[58] M. B. Ferrera, S. P. Litrán, E. D. Aranda, and J. M. A. Márquez, "A converter for bipolar dc link based on sepic-cuk combination," IEEE Trans. Power Electron., vol. 30, no. 12, pp. 6483-6487, Dec 2015.

[59] L. Tan, N. Zhu, and B. Wu, "An integrated inductor for eliminating circulating current of parallel three-level dc-dc converter-based ev fast charger," IEEE Trans. Ind. Electron., vol. 63, no. 3, pp. 1362-1371, March 2016.

[60] Y. Han, J. Kaiser, L. Ott, M. Schulz, F. Fersterra, B. Wunder, and M. Maerz, "Non-isolated three-port dc/dc converter for +-380v dc microgrids," in PCIM Europe 2016; International Exhibition and Conference for Power Electronics, Intelligent Motion, Renewable Energy and Energy Management, May 2016, pp. 1-8.

[61] S. Rezayi, H. Iman-Eini, M. Hamzeh, S. Bacha, and S. Farzamkia, "Dual-output dc/dc boost converter for bipolar dc microgrids," IET Renewable Power Generation, vol. 13, no. 8, pp. 1402-1410, 2019.

[62] H. Ghoddami and A. Yazdani, "A bipolar two-stage photovoltaic system based on three-level neutral-point clamped converter," in 2012 IEEE Power and Energy Society General Meeting, July 2012, pp. 1-8.

[63] V. Yaramasu and B. Wu, "Predictive control of a three-level boost converter and an npc inverter for high-power pmsg-based medium voltage wind energy conversion systems," IEEE Trans. Power Electron., vol. 29, no. 10, pp. 5308-5322, Oct 2014.

[64] M. Shen, A. Joseph, J. Wang, F. Z. Peng, and D. J. Adams, "Comparison of Traditional Inverters and $Z$-Source Inverter for Fuel Cell Vehicles," IEEE Trans. Ind. Electron., vol. 22, no. 4, pp. 1453-1463, 2007.

[65] J. W. Kolar and F. C. Zach, "A novel three-phase utility interface minimizing line current harmonics of high-power telecommunications rectifier modules," IEEE Trans. Ind. Electron., vol. 44, no. 4, pp. 456467, Aug 1997.

[66] S. Prakash P, R. Kalpana, B. Singh, and G. Bhuvaneswari, "Design and implementation of sensorless voltage control of front-end rectifier for power quality improvement in telecom system," IEEE Transactions on Industry Applications, vol. 54, no. 3, pp. 2438-2448, May 2018.

[67] Guanghai Gong, M. L. Heldwein, U. Drofenik, J. Minibock, K. Mino, and J. W. Kolar, "Comparative evaluation of three-phase high-powerfactor ac-dc converter concepts for application in future more electric aircraft," IEEE Trans. Ind. Electron., vol. 52, no. 3, pp. 727-737, June 2005.

[68] L. Hang, B. Li, M. Zhang, Y. Wang, and L. M. Tolbert, "Equivalence of svm and carrier-based pwm in three-phase/wire/level vienna rectifier and capability of unbalanced-load control," IEEE Trans. Ind. Electron., vol. 61, no. 1, pp. 20-28, Jan 2014.

[69] T. Gao, S. Zhang, S. Zhang, and J. Zhao, "A dynamic model and modified one-cycle control of three-level front-end rectifier for neutral point voltage balance," IEEE Access, vol. 5, pp. 2000-2010, 2017. 
[70] M. Hartmann, S. D. Round, H. Ertl, and J. W. Kolar, "Digital Current Controller for a $1 \mathrm{MHz}, 10 \mathrm{~kW}$ Three-Phase Vienna Rectifier," IEEE Trans. Power Electron., vol. 24, no. 11, pp. 2496-2508, Nov 2009.

[71] J. W. Kolar and T. Friedli, "The Essence of Three-Phase PFC Rectifier Systems-Part I," IEEE Trans. Power Electron., vol. 28, no. 1, pp. 176198, Jan 2013.

[72] D. Menzi, D. Bortis, and J. W. Kolar, "A New Bidirectional Three-Phase Phase-Modular Boost-Buck AC/DC Converter," in 2018 IEEE International Power Electronics and Application Conference and Exposition (PEAC), Nov 2018, pp. 1-8.

[73] J. R. R. Zientarski, M. L. da Silva Martins, J. R. Pinheiro, and H. L. Hey, "Series-Connected Partial-Power Converters Applied to PV Systems: A Design Approach Based on Step-Up/Down Voltage Regulation Range," IEEE Trans. Power Electron., vol. 33, no. 9, pp. 7622-7633, Sep. 2018.

[74] — - "Evaluation of Power Processing in Series-Connected PartialPower Converters," IEEE Trans. Emerg. Sel. Topics Power Electron., vol. 7, no. 1, pp. 343-352, March 2019.

[75] P. Purgat, N. van der Blij, Z. Qin, and P. Bauer, "Partially Rated Power Flow Control Converter Modeling for Low Voltage DC Grids," IEEE Trans. Emerg. Sel. Topics Power Electron., pp. 1-1, 2019.

[76] P. Purgat, L. Mackay, M. Schulz, Y. Han, Z. Qin, M. März, and P. Bauer, "Design of a power flow control converter for bipolar meshed lvdc distribution grids," in 2018 IEEE 18th International Power Electronics and Motion Control Conference (PEMC), Aug 2018, pp. 1073-1078.

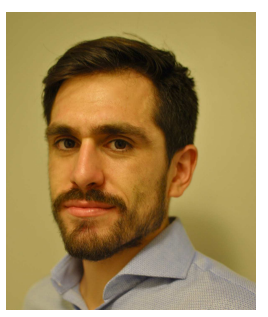

Sebastian Rivera (S'10-M'16) was born in Valparaiso, Chile in 1986. He received the M.Sc. degree in Electronics Engineering from Universidad Tecnica Federico Santa Maria (UTFSM), Chile, in 2011, and the Ph.D. degree in Electrical and Computer Engineering from Ryerson University, Toronto, Canada, in 2015. During 2016 and 2017, received postdoctoral training at the University of Toronto, Canada, and at the Advanced Center of Electrical and Electronic Engineering (AC3E), UTFSM, respectively. In 2018, he joined Universidad de los Andes, Santiago, Chile, where he is currently an Assistant Professor for the Faculty of Engineering and Applied Sciences. He is also an Associate Researcher at the AC3E and the Solar Energy Research Center, Chile.

His research focuses on electric vehicle charging infrastructure, multilevel converters, high efficiency dc-dc conversion, and renewable energy systems.

Dr. Rivera was the recipient of the Emerging Leaders in the Americas Program Scholarship from the Canadian Bureau for International Education in 2010, the Ph.D. Scholarship from the Chilean National Commission for Scientific and Technological Research (CONICYT) in 2011, and the Academic Gold Medal of the Governor General of Canada in 2016.

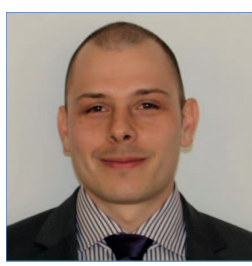

Tomislav Dragičević (S'09-M'13-SM'17) received the M.Sc. and the industrial Ph.D. degrees in Electrical Engineering from the Faculty of Electrical Engineering, Zagreb, Croatia, in 2009 and 2013, respectively. From 2013 until 2016 he was a Postdoctoral research associate at Aalborg University, Denmark. From March 2016 until March 2020 he was an Associate Professor at Aalborg University, Denmark. From April 2020 he is a Professor at the Technical University of Denmark.

He made a guest professor stay at Nottingham University, UK during spring/summer of 2018. His research interest is application of advanced control, optimization and artificial intelligence inspired techniques to provide innovative and effective solutions to emerging challenges in design, control and cyber-security of power electronics intensive electrical distributions systems and microgrids. He has authored and coauthored more than 220 technical publications (more than 100 of them are published in international journals, mostly in IEEE), 8 book chapters and a book in the field.

He serves as Associate Editor in the IEEE TRANSACTIONS ON INDUSTRIAL ELECTRONICS, in IEEE Emerging and Selected Topics in Power Electronics and in IEEE Industrial Electronics Magazine. Dr. Dragičević is the recipient of the Končar prize for the best industrial $\mathrm{PhD}$ thesis in Croatia, a Robert Mayer Energy Conservation award, and an Alexander von Humboldt fellowship for experienced researchers. He is currently listed as one of the top 5 trending authors in Engineering globally by Microsoft Academic.

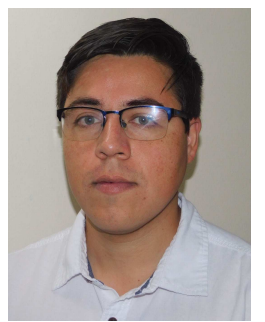

Ricardo Lizana F. (S'11-M'16) was born in Rancagua, Chile in 1985. He received his M.Sc. and D.Sc. degrees in electronic engineering from Universidad Tecnica Federico Santa Maria, Valparaiso, Chile, in 2011 and 2015, respectively.

$\mathrm{He}$ joined Universidad Catolica de la Santisima Concepcion, Concepcion, Chile, in 2015, where he is currently an Assistant Professor at the Departamento de Ingeniería Eléctrica. During 2017 he was a postdoctoral fellow at Duke University.

His main research interests include high power converters, HVDC transmission systems and renewable energy systems.

Dr. Lizana received the Ph.D. Scholarship from the Chilean National Commission for Scientific and Technological Research (CONICYT) in 2011, the Emerging Leaders in the Americas Program Scholarship from the Canadian Bureau for International Education in 2012 and the Second Prize Paper Award of the IEEE Transactions on Power Electronics in 2015.

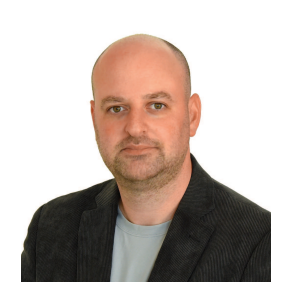

Samir Kouro (S'04-M'08-SM'17) received the M.Sc. and Ph.D. degrees in electronics engineering from the Universidad Tecnica Federico Santa Maria (UTFSM), Valparaíso, Chile, in 2004 and 2008, respectively

In 2007, he joined the Electronics Engineering Department, UTFSM, as a Research Associate, where he currently holds a Professor position. From 2009 to 2011, he was a Postdoctoral Fellow with the Department of Electrical and Computer Engineering, Ryerson University, Toronto, ON, Canada. Since 2019 he is Director of Innovation and Technology Transfer at UTFSM. He is a Founding Member and a Principal Investigator of the Solar Energy Research Center, Chile, one of the national priority areas centers of excellence of Chile, and a Founding Member and a Deputy Director of the Advanced Center of Electrical and Electronics Engineering, Chile, one of the technology transfers centers of excellence in Chile. He has coauthored one book, 9 book chapters, and more than 180 refereed journal and conference papers, and 3 patents. His current research interests include power electronics, renewable energy conversion systems (photovoltaic and wind), and electromobility.

Dr. Kouro was included in the 2018 Clarivate Analytics Highly Cited Researcher List, and has been the recipient of the 2016 IEEE Industrial Electronics Bimal K. Bose Award for Industrial Electronics Applications in Energy Systems, 2015 IEEE Industrial Electronics Society J. David Irwin Early Career Award, 2012 IEEE Power Electronics Society Richard M. Bass Outstanding Young Power Electronics Engineer Award, 2012 IEEE Industry Applications Magazine First Prize Paper Award, 2012 IEEE Transactions on Industrial Electronics Best Paper Award, and 2008 IEEE Industrial Electronics Magazine Best Paper Award. He has served as a Special Session Organizer and the Chair of 12 special sessions in conferences and has been a Guest Editor of five special sections and issues in several IEEE journals.

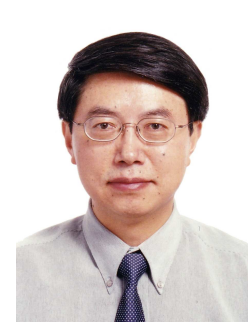

Bin Wu (S'89-M'92-SM'99-F'08) received his M.A.Sc. and Ph.D. degrees in electrical and computer engineering from the University of Toronto, Toronto, ON, Canada in 1989 and 1993, respectively.

He joined Ryerson University, Toronto, in 1993, where he is currently a Professor Emeritus. $\mathrm{He}$ has published more than 450 technical papers, authored/coauthored several Wiley-IEEE Press books, and holds more than 30 granted/pending US/European patents in the area of power conversion, medium voltage drives, and renewable energy systems.

Prof. Wu is a Fellow of Academy of Science of Royal Society of Canada (RSC), the Engineering Institute of Canada (EIC) and the Canadian Academy of Engineering (CAE). He was the recipient of the Academic Gold Medal of the Governor General of Canada in 1993, the Premier's Research Excellence Award in 2001, the NSERC Synergy Award for Innovation in 2002, the Ryerson Distinguished Scholar Award in 2003, Ryerson YSGS Outstanding Contribution to Graduate Education Award and Professional Engineers Ontario (PEO) Engineering Excellence Medal in 2014 